\title{
Miniaturized optical communications modules for space applications
}

J. Edmunds, L. Henwood-Moroney, N. Hammond, E. Prowse, K. Hall, et al.

J. Edmunds, L. Henwood-Moroney, N. Hammond, E. Prowse, K. Hall, L. Szemendera, N. Davoudzadeh, P. Holland, K. Simpson, C. Palmer, L. Stampoulidis, P. Kean, M. Welch, E. Kehayas, "Miniaturized optical communications modules for space applications," Proc. SPIE 11852, International Conference on Space Optics - ICSO 2020, 118521K (11 June 2021); doi: 10.1117/12.2599247

SPIE Event: International Conference on Space Optics - ICSO 2021, 2021, Online Only 


\section{International Conference on Space Optics-ICSO 2020}

Virtual Conference

30 March-2 April 2021

Edited by Bruno Cugny, Zoran Sodnik, and Nikos Karafolas
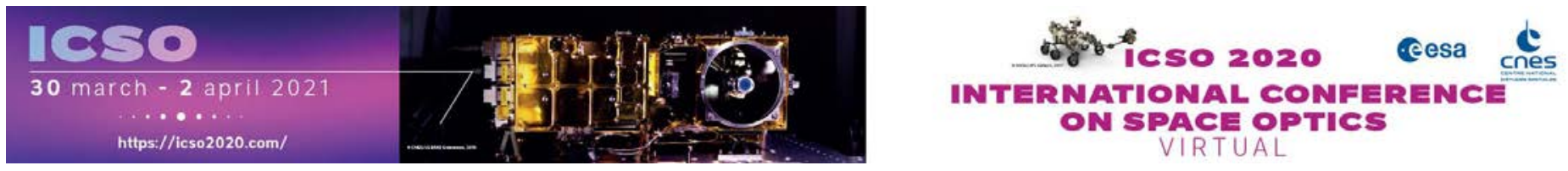

\section{Miniaturized optical communications modules for space applications}

\section{Cesa isonematang lecnes}

International Conference on Space Optics - ICSO 2020, edited by Bruno Cugny, Zoran Sodnik, Nikos Karafolas, Proc. of SPIE Vol. 11852, 118521K · (c) 2021 ESA and CNES

CCC code: $0277-786 \mathrm{X} / 21 / \$ 21 \cdot$ doi: $10.1117 / 12.2599247$ 


\title{
Miniaturized Modules for Space Based Optical Communication
}

\author{
J. Edmunds ${ }^{a}$, L. Henwood-Moroney ${ }^{a}$, N. Hammond ${ }^{a}$, E. Prowse ${ }^{a}$, K. Hall ${ }^{a}$, L. Szemendera ${ }^{a}$, N. \\ Davoudzadeh $^{b}$, P. Holland ${ }^{\mathrm{a}}$, K. Simpson ${ }^{\mathrm{a}}$, C. Palmer ${ }^{\mathrm{a}}$, L. Stampoulidis ${ }^{\mathrm{c}}$, P. Kean ${ }^{\mathrm{a}}$, M. Welch ${ }^{\mathrm{a}}$, \\ E. Kehayas ${ }^{\mathrm{a}}$ \\ ${ }^{\mathrm{a}} \mathrm{G} \& \mathrm{H}$ (Torquay), Broomhill Way, Torquay, Devon, TQ2 7QL, UK. \\ ${ }^{\mathrm{b}} \mathrm{G} \& \mathrm{H}$ (Boston), 7 Oak Park Drive Bedford, MA, 01730, USA \\ ${ }^{c}$ Leo Space Photonics, 27 Neapoleos Street, Agia Paraskevi, 15341, Athens, Greece.
}

\begin{abstract}
We present recent progress in developing miniaturized optical transmitters and receiver amplifiers for space communications. Three C-band high-speed optical transmitter designs are presented: a bespoke $300 \mathrm{~mW}$ version as part of TNO's "SmallCat" terminal to fly on-board NordSat and two variants that provide $300 \mathrm{~mW}$ and 3 W of optical power complying to standard cubesat form factors. In addition to these transmitters, an ultra-small form factor, high gain, low noise amplifier, for boosting received signals is presented.
\end{abstract}

Keywords: Free Space Optical Communications, Laser Communications, Space Photonics, Cubesats, Laser Transmitters, Constellations.

\section{INTRODUCTION}

In the last few years G\&H have supplied optical components and subsystems into a range of spaced-based technology demonstrators, pathfinder missions and pioneering commercial ventures. Most notably, G\&H have recently been involved in JAXA's laser communication demonstrator LUCAS, which employs a high power amplifier for transmission and low noise receiver amplifier to boost the received signal ${ }^{1}$. The market and in many cases governmental agencies, are transitioning beyond pathfinder missions, and looking to use optical communications as the mainstream solution for high-speed network services. The number of satellites employing or planning to employ laser terminals are growing rapidly. At the same time the size of these systems is shrinking rapidly, with commercial pressure pushing suppliers to reduce size, mass, power consumption and lead time, whilst increasing functionality and controlling cost and quality. To meet this demand and outline capability, four miniaturized designs of transmitter and receivers for LEO laser-comms applications are the outlined in this paper. These four designs are referred to here as "SmallCat", "Perseus low power (LP)", "Perseus high power (HP)" and "Orionas" with images provided in Figure 1 and a brief description in Table 1.

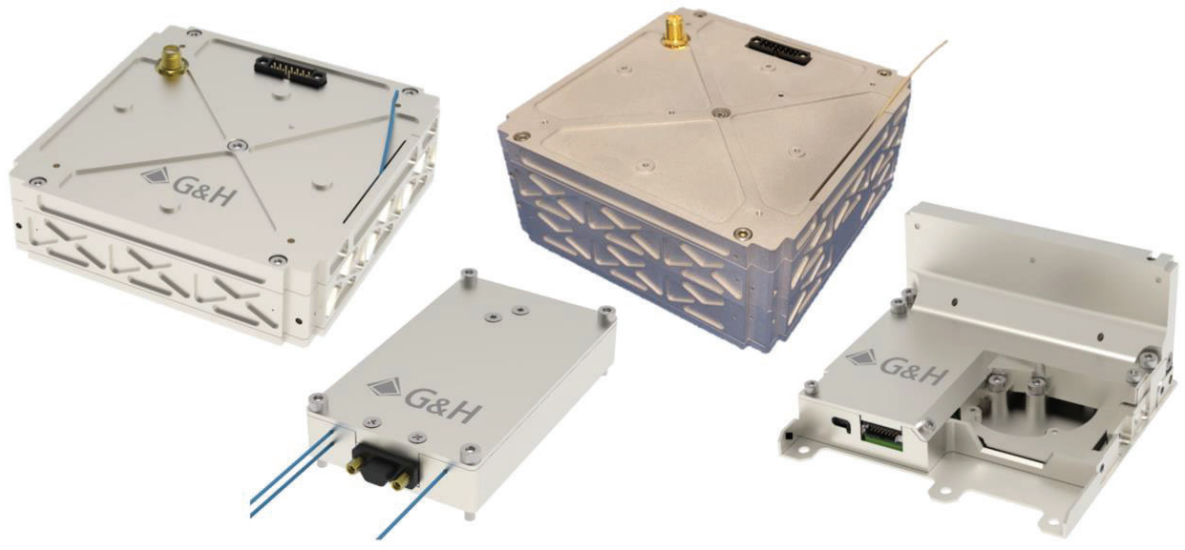

Figure 1. Rendered CAD Images and photos of G\&H miniaturized optical communications modules. Top-left: $300 \mathrm{~mW}$ Perseus LP laser Transmitter Module. Top-Right: 3 W Perseus HP laser Transmitter Module. Bottom-Mid: Orionas low noise, high gain booster receiver amplifier Bottom-Right: SmallCat Laser Transmitter Module. 
The three designs of transmitters are based on amplification of a directly modulated DFB, with SmallCat and Perseus LP employing a core pumped Er amplifier stage to output $>300 \mathrm{~mW}$ and Perseus HP employing an additional Er/Yb amplification stage to achieve $>3 \mathrm{~W}$ output power. The receiver amplifier, Orionas, employs dual stage core pumped amplification with mid stage filtering to achieve $>50 \mathrm{~dB}$ of gain for a $-45 \mathrm{dBm}$ input. The Perseus designs are currently undergoing assembly integration and test (AIT) of engineering model (EM) builds with a view to producing a flight grade unit for a partner demonstration in 2022. A proto-flight model of the SmallCat transmitter is in AIT for an in-orbit demonstration on TNO's SmallCat platform scheduled for mid-2021 on-board NordSat-TD. An EM of the Orionas receiver is currently in AIT to feed into the Orionas Horizon 2020 project that bears the same name that focuses on miniaturized space comms.

\begin{tabular}{|c|c|c|c|c|}
\hline $\begin{array}{l}\text { Product } \\
\text { Name }\end{array}$ & Description & $\begin{array}{c}\text { Mass } \\
\text { Density }\end{array}$ & Size Envelope & $\begin{array}{c}\text { Power } \\
\text { Consumption }\end{array}$ \\
\hline $\begin{array}{l}\text { SmallCat } \\
\text { (Laser } \\
\text { Transmitter) }\end{array}$ & $\begin{array}{l}\text { Directly modulated } \mathbf{3 0 0} \mathbf{~ m W} \mathbf{C} \text {-band } \\
\text { transmitter, for on off keying at } 1 \mathrm{Gbit} / \mathrm{s} \text {. } \\
\text { Direct interface to electro-optical and } \\
\text { optoelectronic components. } \\
\text { Bespoke form factor for TNO's SmallCat } \\
\text { terminal. }\end{array}$ & $\begin{array}{c}191 \mathrm{~g} \\
\approx 1.6 \mathrm{~g} / \mathrm{cm}^{3}\end{array}$ & $96 \times 92 \times 53 \mathrm{~mm}$ & $\begin{array}{c}<5 \mathrm{~W} \text { Typical } \\
\text { for } 300 \mathrm{~mW} \\
\text { out }\end{array}$ \\
\hline $\begin{array}{l}\text { PerseusLP } \\
\text { (Laser } \\
\text { Transmitter) }\end{array}$ & $\begin{array}{l}\text { Directly modulated } \mathbf{3 0 0} \mathbf{~ m W} \text { C-band } \\
\text { transmitter, for on off keying at }>1 \mathrm{G} \text { bit/s } \\
\text { (target } 10 \mathrm{Gbit} / \mathrm{s} \text { ). } \\
\text { Command and Montoring through digital } \\
\text { communication interface with onboard } \\
\text { microcontroller, and power conditioning. } \\
\text { Generic Cubesat form factor }\end{array}$ & $\begin{array}{c}400 \mathrm{~g} \\
\approx 1.5 \mathrm{~g} / \mathrm{cm}^{3}\end{array}$ & $100 \times 100 \times 26.5 \mathrm{~mm}$ & $\begin{array}{c}10 \mathrm{~W} \text { Typical } \\
\text { for } 300 \mathrm{~mW} \\
\text { out }\end{array}$ \\
\hline $\begin{array}{l}\text { Perseus HP } \\
\text { (Laser } \\
\text { Transmitter) }\end{array}$ & $\begin{array}{l}\text { Directly modulated } \mathbf{3} \mathbf{W} \text { C-band } \\
\text { transmitter, for on off keying at }>1 \text { Gbit/s } \\
\text { (target } 10 \mathrm{Gbit} / \mathrm{s}) \text {. } \\
\text { Command and Montoring through digital } \\
\text { communication interface with onboard } \\
\text { microcontroller, and power conditioning. } \\
\text { Generic Cubesat form factor }\end{array}$ & $\begin{array}{c}650 \mathrm{~g} \\
\approx 1.6 \mathrm{~g} / \mathrm{cm}^{3}\end{array}$ & $100 \times 100 \times 42 \mathrm{~mm}$ & $\begin{array}{c}35 \mathrm{~W} \text { Typical } \\
\text { for } 3 \mathrm{~W} \text { out }\end{array}$ \\
\hline $\begin{array}{l}\text { Orionas } \\
\text { (Reciever } \\
\text { amplfier) }\end{array}$ & $\begin{array}{l}\text { C-band low noise receiver amplifier } \\
\text { providing }>50 \mathrm{~dB} \text { of gain and } \sim 5 \mathrm{~dB} \\
\text { Noise figure for }-45 \mathrm{dBm} \text { input } \\
\text { Command and Montoring through digital } \\
\text { communication interface with onboard } \\
\text { microcontroller, power conditioning. } \\
\text { Credit card sized form factor }\end{array}$ & $\begin{aligned} & 100 \mathrm{~g} \\
\approx & 1.3 \mathrm{~g} / \mathrm{cm}\end{aligned}$ & $90 \times 54 \times 15.5 \mathrm{~mm}$ & < 5 W Typical \\
\hline
\end{tabular}

Table 1. Summary of the miniaturized optical communications modules designs outlined in this paper. Density is calculated with respect to space claimed by the module and, size envelope being the maximum extend of the module in each axis. All modules were designed for low earth orbit operation. 


\section{INTEGRATION LEVEL}

Laser transmitters can be manufactured at a range of integration levels, with the interface to optical elements frequently being variable; this is the case behind the SmallCat, Perseus LP and Perseus HP efforts. Figure 2 shows the architectural difference between the transmitter designs, with the Perseus providing signal and power conditioning managed via a microcontroller and command and control through a digital serial interface. The microcontroller provides all the functionality one would expect from a terrestrial telecoms transmitters, such as power control, over-temperature protection and status reporting. The electronics componentry is high-spec COTS, with derating and design for increased reliability. The integrated firmware reflects best practice terrestrial programming: radiation resilience of the unit is achieved through physical shielding, though not immune to latch up events above certain TID levels. An RF amplifier is provided on Perseus LP and HP to boost and condition the input data modulation for instance directly from an FPGA. Figure 3 shows a system level schematic of the Orionas module. As with the Perseus designs, the small form factor housing also incorporates power conditioning and command and control through a microcontroller.

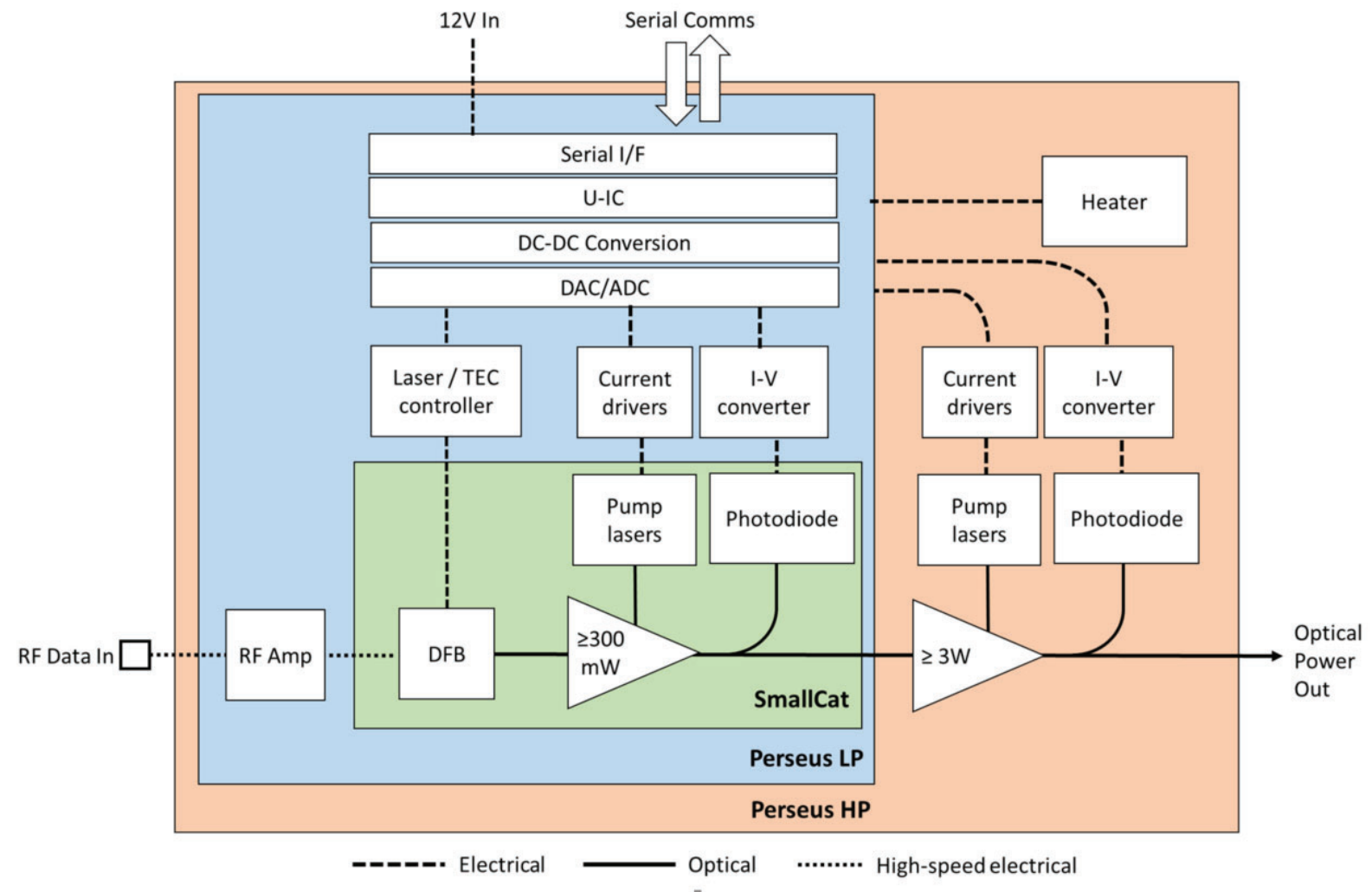

Figure 2. A simplified system level diagram of the different integration levels of the transmitter design of SmallCat, Perseus LP and Perseus HP. 


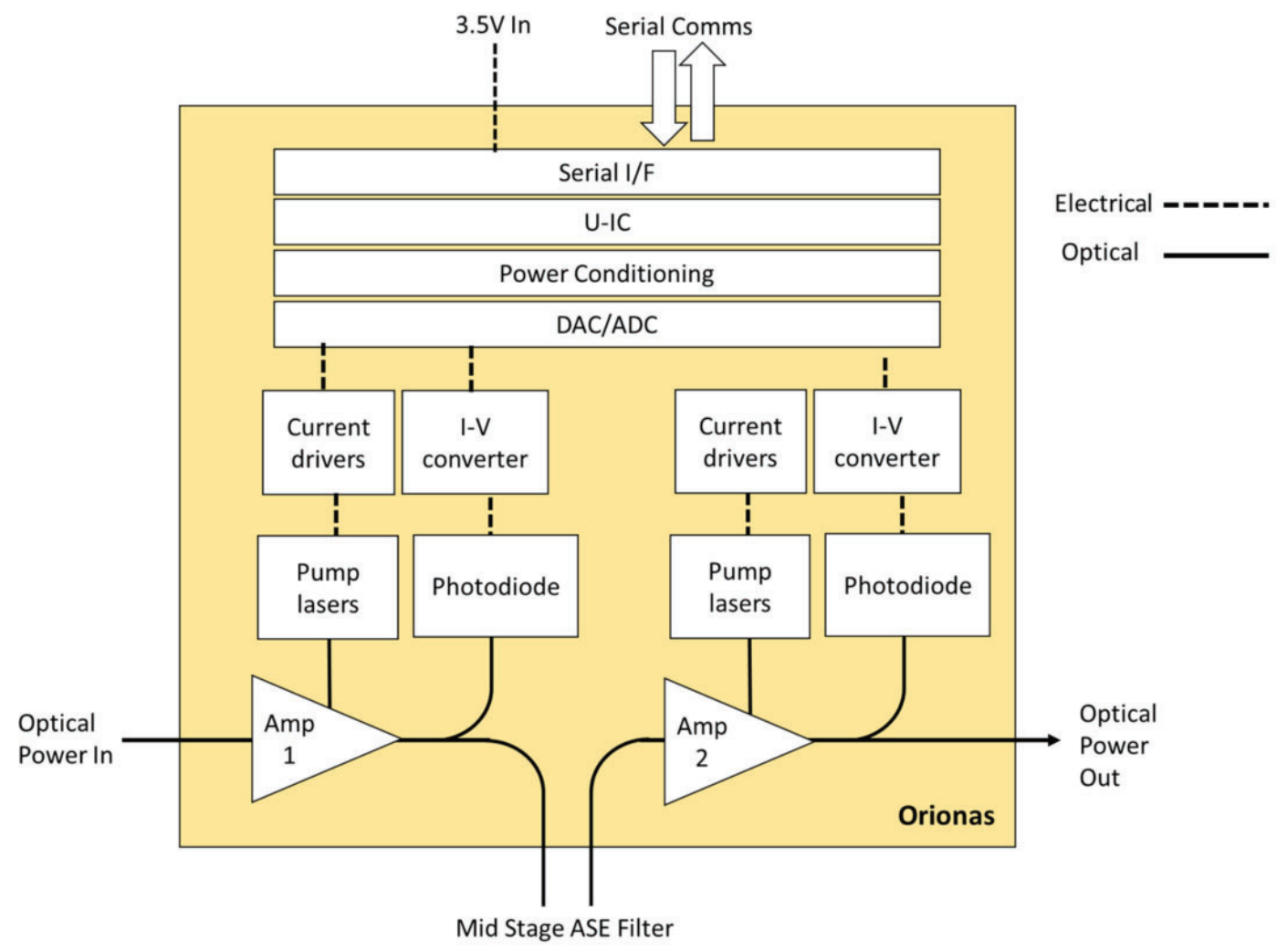

Figure 3. A simplified system level diagram of Orionas receiver design.

\section{TRANSMITTER OPTICAL PERFORMANCE}

For the SmallCat and Perseus laser transmitter designs the input data is encoded into the optical domain via direct modulation of the drive current of a distributed feedback (DFB) laser, operating close to threshold. Though the optical performance of direct modulation presents trade-offs compared to other techniques such as external modulation, it enables a compact, power efficient design, capable of Gbit/s data encoding. G\&H design and manufacture flight proven space grade DFBs and have demonstrated modulation bandwidths of $>13 \mathrm{GHz}$ (Figure 4). An example eye diagram from a system at $1 \mathrm{GHz}$ modulation is shown in Figure 5.

The transmitter designs detailed within this paper amplify a milli-Watt level signal from the DFB using a one or twostage EDFA. The EDFA is built around G\&H space grade fiber optic components and up-screened COTS components ${ }^{2}$. Passive-cooling is used, with the exception of a power-efficient TEC to control the DFB ( $<100 \mathrm{~mW}$ heat load), and an integrated heating element to bring the module up to operating temperature.

SmallCat and Perseus LP (300 mW output power) transmitter designs employ a core pumped erbium-doped amplifier stage, the typical raw electrical to optical conversion efficiency of which is typically $\geq 7 \%$. The Perseus HP transmitter employs a subsequent ErYb amplifier stage to achieve a $3 \mathrm{~W}$ output, the raw electrical to optical conversion efficiency of this stage is higher at typically $\geq 15 \%$. 


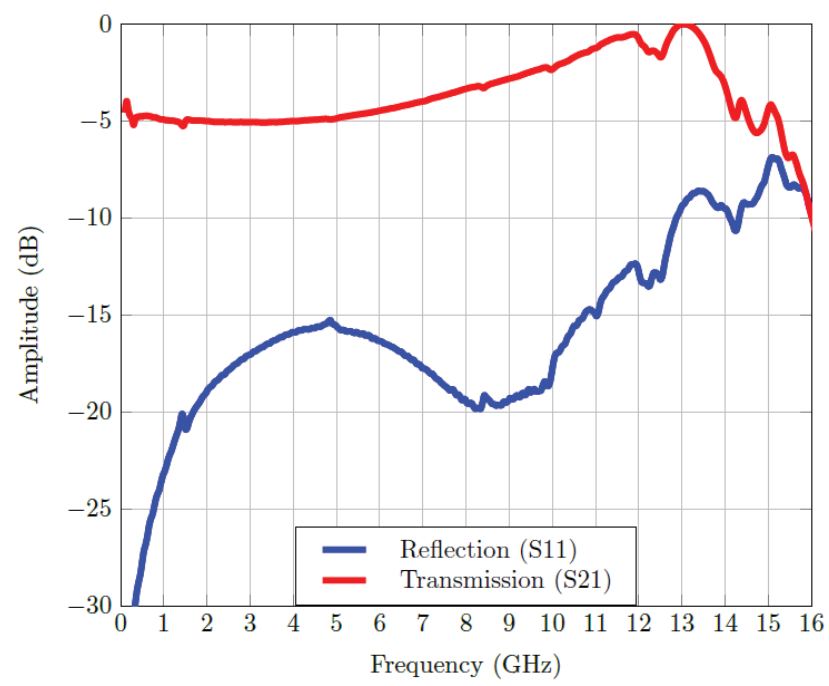

Figure 4. S11 and S21 parameters from a G\&H DFB (AA0701).

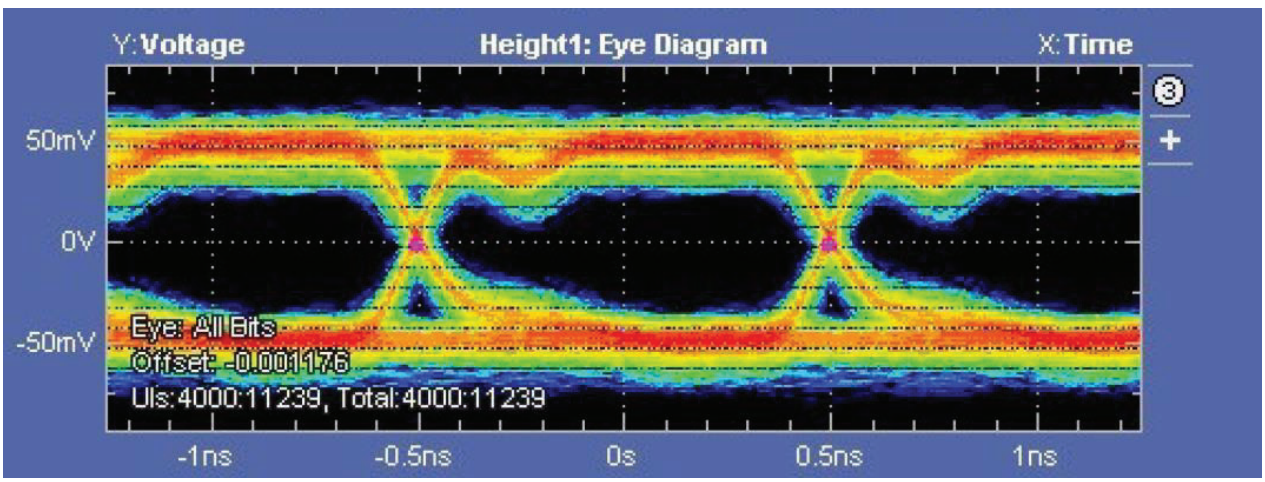

Figure 5. Eye diagram from SmallCat transmitter for $1 \mathrm{GHz}$ PRBS. Shown here as an initial demonstration and captured during the initial module configuration. Here good eye opening is shown alongside a slight oscillation that was later rectified.
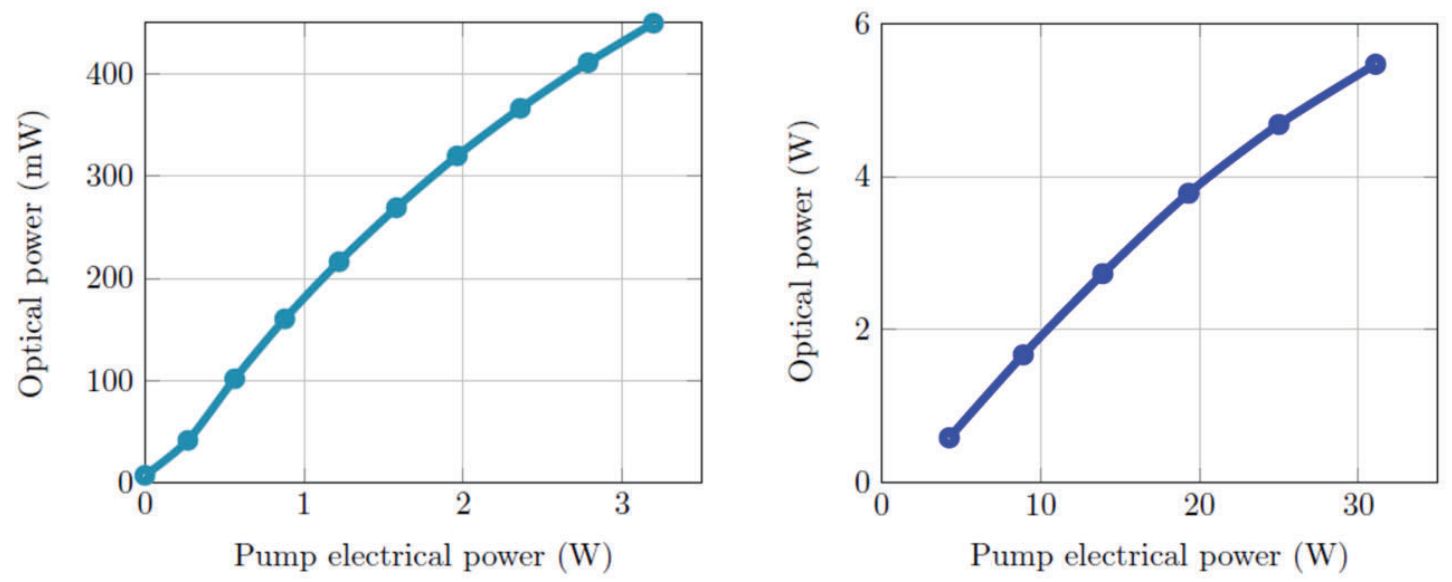

Figure 6. Typical electro-optical conversion curves for (left) core pump amplifier stage employed on SmallCat and Perseus LP designs, (right) the addition cladding pumped amplifier stage on Perseus HP. 


\section{RECEIVER OPTICAL PERFORMANCE}

A high-efficiency and low-noise amplifier is required at the receiver end to close the inter-satellite link or uplink in case of direct downlinks with optical uplink capabilities. With a $-45 \mathrm{dBm}$ input signal, the Orionas receiver demonstrates $>50$ $\mathrm{dB}$ gain across the $\mathrm{C}$-band. To achieve this high level of gain, two separate amplifications stages are required. Spectra filtering between the amplification stages to reject out of band ASE passing is key to an efficient system; without this the second amplification stage gain is dominated by the amplification of ASE - particularly for low input power levels. Figure 7 shows example results with $100 \mathrm{GHz}$ bandwidth ASE filters, one can observe that with filtering gain is increased, particularly for low input powers. One can also observe that the filter reduces wavelength dependent gain. Due to the low-loss optical architecture, excellent noise figures of $\sim 5 \mathrm{~dB}$ are delivered across the C-band.

The impressive form-factor of the receiver is enabled through the use of specialized fibre and fibre-based components with a reduced cladding diameter. This allows for a smaller bend-radius to be realized for the same level of static loading, meaning the fibre can be coiled tighter without increasing the risk of fatigue failure over the unit lifetime.
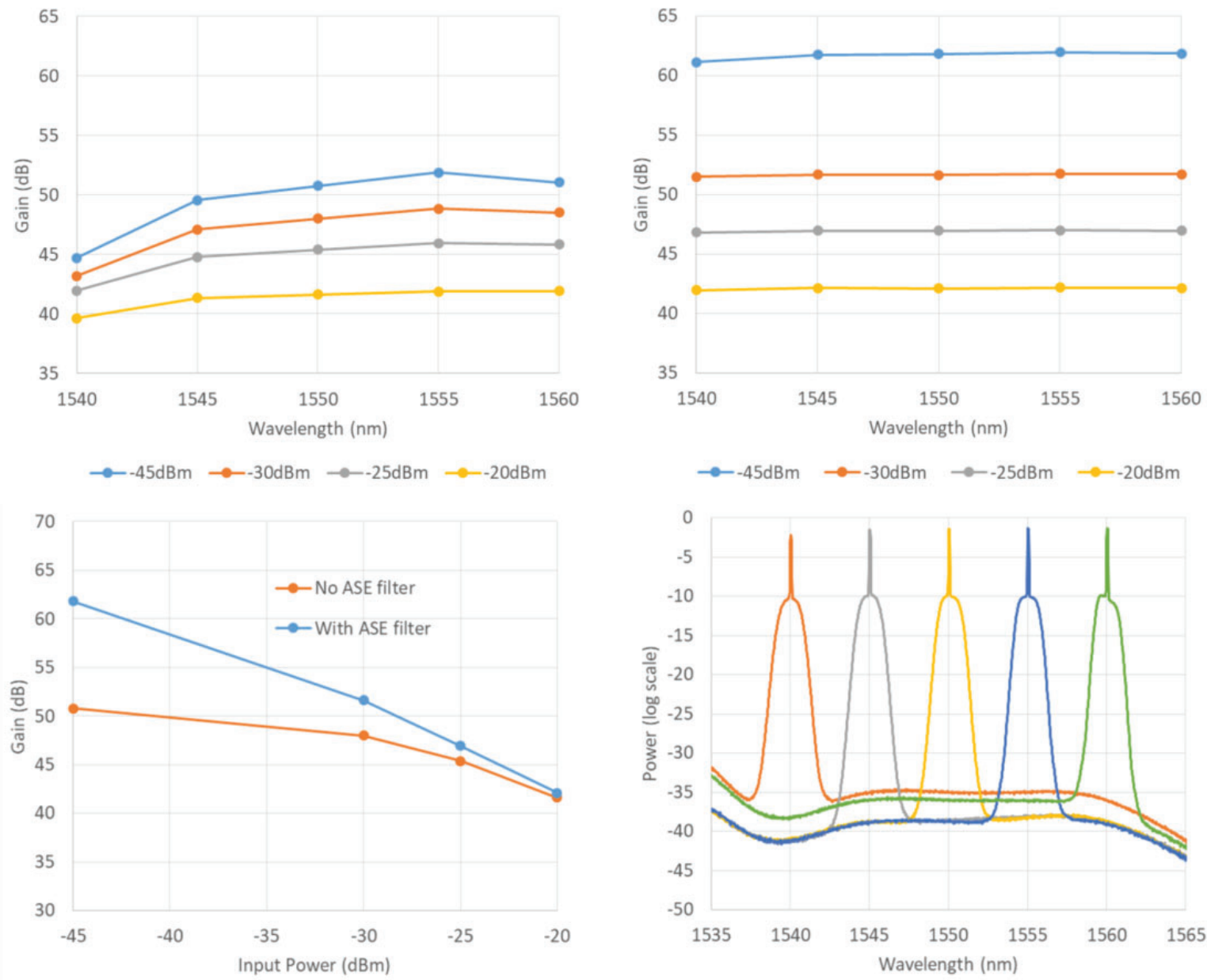

Figure 7. Top-left \& Top-Right: Gain of Orionas amplifier as a function of input power and wavelength, with (right) and without (left) a $100 \mathrm{GHz}$ bandwidth filter between the amplification stages, Bottom-Left: Performance as a function of input power, with and without ASE filter, for a $1550 \mathrm{~nm}$ signal. Bottom-Right: Example output spectra for a $-45 \mathrm{dBm}$ input signal at 1540, 1545, 1550, 1555 and $1560 \mathrm{~nm}$ with mid-stage ASE filtering employed. 


\section{ENVIROMENTAL ROBUSTNESS}

The typical approach taken when qualifying a system for space (or indeed any environment), is to first select components or subsystems that have a quantified and suitable operating range. The integration of these component subsystems, then must ensure operation within these operating ranges whilst minimizing size, mass and manufacturing cost.

The commercialization of the free-space optical communications market and the emergence of New Space has set a precedent for cost-effective photonic solutions. Select COTS components are used across the outline designs, leveraging G\&H's heritage in hi-reliability and space-grade photonic products ${ }^{2}$. With the exception of the digital and analogue electronics, all other COTS components employed have undergone environmental testing to understand their suitability for space environments ${ }^{3-7}$.

\subsection{Mechanical Assembly Design}

Three principle environmental key challenges exist when designing a photonic module suitable for a space: radiation shielding, heat dissipation and mechanical robustness. Each come with their own impact on the size, mass, and cost of the unit.

Miniaturizing designs necessitates an increase in density, owing to the smaller volume. Most assemblies for pathfindertype missions have densities between $0.8-1.1 \mathrm{~g} / \mathrm{cm}^{3}$. The designs outlined here all have densities $>1.3 \mathrm{~g} / \mathrm{cm} 3$, with the SmallCat and Perseus HP having a density of $\approx 1.6 \mathrm{~g} / \mathrm{cm}^{3}$ (Table 1 ) - highlighting the highly compact nature of the designs. This increase in density generally aids mechanical robustness as vibrational modes are pushed to higher frequencies with the assembly becoming stiffer. The increased density also aids radiation shielding as closely located components can share shielding. There is a minimum aluminum shielding provided by the assembly wall that varies with design between $1.5 \mathrm{~mm}$ and $3 \mathrm{~mm}$, with select localized internal shielding; this is sufficient for low earth orbit type applications. Increasing the density of assemblies however can lead to thermal challenges, as it necessary to co-locate heat sources - this being especially pertinent to Perseus HP which when operating at $3 \mathrm{~W}$ output can produce a heat load of $>30 \mathrm{~W}$.

To create optimized designs, finite element analysis (FEA) is a key design tool that can be used to quickly assess the thermal/vibrational effects of mechanical changes. This enables one to iterate the design to reduce size and mass whilst maximizing mechanical robustness and thermal performance. Section 5.2 and 5.3 show example vibrational analysis and thermal modelling results for the assemblies.

\subsection{Vibrational Analysis}

Vibrational analyses of each of the assemblies was performed to optimise the use of mass and fixing locations. Table 2 and Figure 8 show select results. The reasonant frequencies simulated are much higher than the main excitational bands generated by launchers, which are typically peak at frequencies $<500 \mathrm{~Hz}$. Furthermore all fundamental modes correspond to movement of surfaces onto which critial components aren't mounted.

\begin{tabular}{|c|c|c|c|}
\hline Mode Number & SmallCat & Perseus HP & Orionas \\
\hline 1 & $2204 \mathrm{~Hz}$ & $1880 \mathrm{~Hz}$ & $1353 \mathrm{~Hz}$ \\
\hline 2 & $3307 \mathrm{~Hz}$ & $1903 \mathrm{~Hz}$ & $2156 \mathrm{~Hz}$ \\
\hline 3 & $4101 \mathrm{~Hz}$ & $2264 \mathrm{~Hz}$ & $2796 \mathrm{~Hz}$ \\
\hline 4 & $4154 \mathrm{~Hz}$ & $3257 \mathrm{~Hz}$ & $2816 \mathrm{~Hz}$ \\
\hline 5 & $4186 \mathrm{~Hz}$ & $3282 \mathrm{~Hz}$ & $3216 \mathrm{~Hz}$ \\
\hline
\end{tabular}

Table 2. First five computed vibrational modes of the SmallCat. Persues HP and Orionas assemblies. The high vibrational frequencies indicate very stiff assemblies. These values where computed from the metalwork as select components only, with most housed componentry being added as non-structural mass to produce a worse case analysis. 

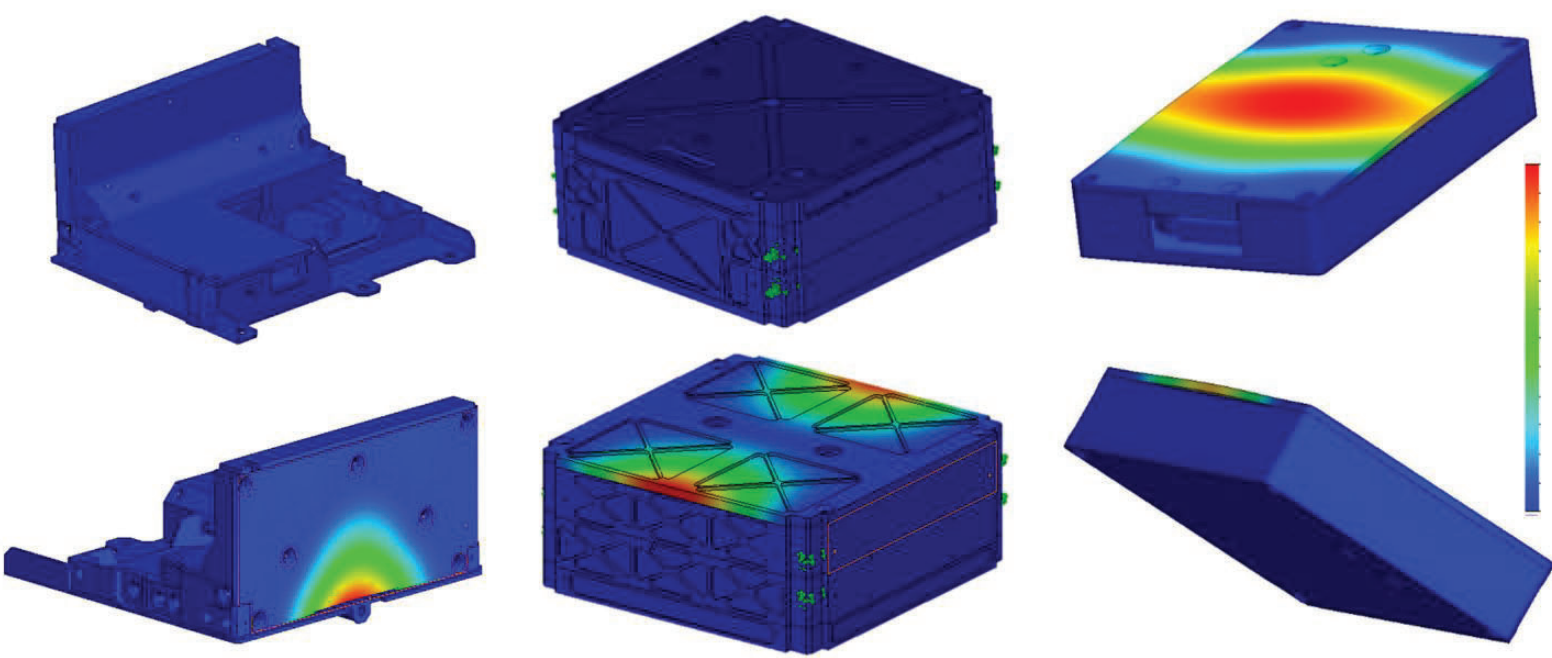

Figure 8. Visualizations from two angles of the lowest vibrational modes of the SmallCat. Perseus HP and Orionas assemblies. The colour scale is linear and arbitrarily scaled for each assembly to best visualise the vibrational mode.

\subsection{Thermal Analysis}

As explained in the previous sub-section, one of the key challenges of miniturizing laser modules is thermal management; this challenge being especially pronounced for high thermal load of the Perseus HP module.

Due to the importance of optimising thermal performance many design iterations and simulations were run, a subset of which are shown in Figure 9. All modelling assumed conductive heat transfer only, with radiative transfer being omitted, to reflect a worst-case analysis. The effect of interface resistance between joined metalwork elements was included, as it is an important source of temperature gradients. Broadly two types of thermal modelling were performed; steady state modelling of heat removal into a satelitte heatsink - this relates to the module being in operation long enough to reach a thermal equilibrium and controlling temperature gradients to the heatsink is the target. The second form of modelling performed was transient modelling, where no (or limited) heat extraction from the assembly is modelled and the uniformity of heating through the assembly was assessed - this relating to a low duty cycle use cases; for example the laser power on as it passes over a ground station.

In these simulations only the metalwork and key components were modelled, with heatloads being applied to component mounting locations. The omission of the additional heat capacity of excluded components increases the absolute temperatures seen in transient modelling; in line with a worse case analysis. 


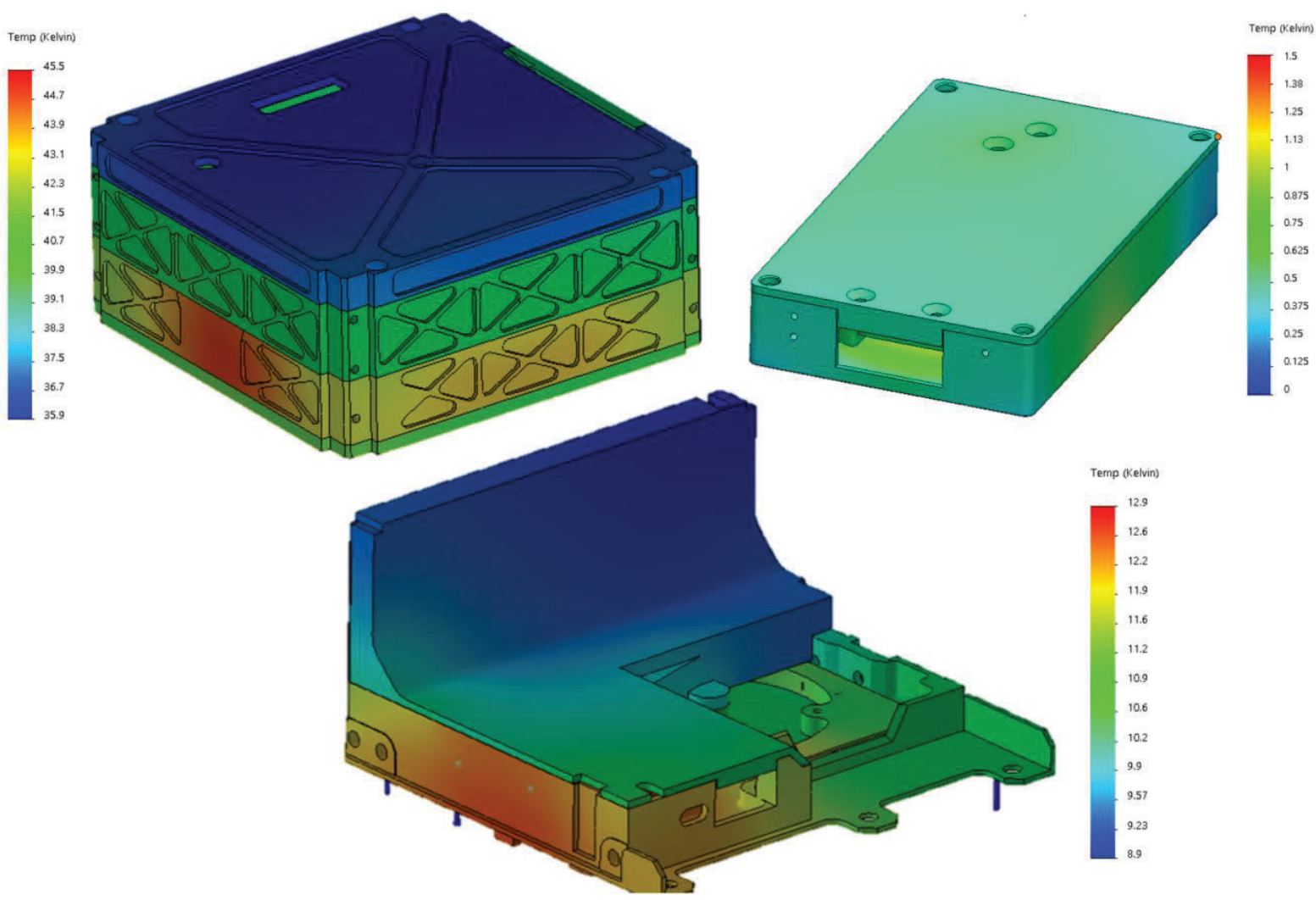

Figure 9. Example simulated thermal profiles for the Perseus HP, Orionas and SmallCat modules. The Perseus HP image (topleft) represents the simulated thermal performance under transient operation. An end of life (EOL) heat load of $43 \mathrm{~W}$ was distributed across the metalwork that is initial a uniform $0 \mathrm{k}$. After $350 \mathrm{~s}$ a $9.6 \mathrm{k}$ temperature gradient exists across the metalwork, with maximum temperature being $4.2 \mathrm{k}$ above that of a uniform distribution of the heat. The Orionas image (topright) represents steady state operation attached to a heatsink, with very low temperature gradients being seen. The SmallCat image (bottom), like Perseus HP, represents transient operation, with a $4.3 \mathrm{~W}$ EOL heat load being applied for $300 \mathrm{~s}$, the results showing a $4 \mathrm{k}$ temperature gradient existing across the metalwork.

\section{CONCLUSION}

This paper highlighted our recent development work in miniaturizing optical transmitters and receiver amplifiers for space communications. Three CubeSat-compatible C-band optical transmitter designs were presented as well as an ultrasmall form factor receiver amplifier. One of these transmitters will be system integrated into TNO's "SmallCat" laser terminal with an in orbit demonstration of free space communications scheduled for early 2022.

\section{ACKNOWLEDGEMENT}

This project has received funding from the European Space Agency's ARTES programme "Miniaturized Laser-Comm Transmitters for Small Satellite Platforms" and the European Union's Horizon 2020 research and innovation programme under the Grant Agreement No. 822002. We would like to thank colleagues from the Free-Space Optical Communications team at TNO for the fruitful collaboration. 


\section{REFERENCES}

[1] Press Release. "Successful Launch of Satellite laser communication system" G\&H, 23 December 2020 https://gandh.com/successful-launch-of-satellite-laser-communication-system/ (10 February 2021)

[2] S. Kehayas. "Space Photonics: A Platform Technology for Satellite Systems" EuroPhotonics, September 2017. www.europhotonics-digital.com/europhotonics/2017autumn/ (10 February 2021)

[3] Welch, M., J. Edmunds, J. Crabb, E. Prowse, K. Hall, M. Kechagias, R. Elliott, and E. Kehayas. "High-power booster optical fibre amplifiers for satellite communications." In Free-Space Laser Communications XXXII, vol. 11272, p. 112720X. International Society for Optics and Photonics, (2020).

[4] L. Stampoulidis, E. Kehayas, M. Kechagias, G. Stevens, L. Henwood-Moroney, P. Hosking, and A. Robertson, "Radiation-hard Mid-power Booster Optical Fiber Amplifiers for High-speed Digital and Analogue Satellite Laser Communication Links," International Conference on Space Optics (ICSO) 2014.

[5] L. Stampoulidis, J. Edmunds, M. Kechagias, G. Stevens, J. Farzana, M. Welch, and E. Kehayas, "Radiationresistant optical fiber amplifiers for satellite communications," Proc. SPIE 10096, 100960H (2017).

[6] E. Kehayas, J. Edmunds, C. Palmer, C. Coopman, E. Kehayas, J. Edmunds, C. Palmer, C. Coopman, R. Webb, M. Tuci, K. Simpson, M. Welch, and L. Stampoulidis, "Space qualification of multi-channel optical fiber amplifier for low Earth," Proc. of SPIE Vol. 10524, 105240Z (2018)

[7] P. Henderson, A. Norman, J. Macdougal, P. Naylor, E. Kehayas, L. S. How, S. Lhuillier, A. Bensossan, and M. Zahir, "Space Validation of 1550nm DFB Laser Diode Module," International Conference on Space Optics, (2018). 